\title{
Transformação Pedagógica e (Auto)Formação
}

\section{Docente}

\section{Pedagogical Transformation and Professor (Self)Training}

\author{
Manolita Correia Lima \\ Taiguara de Freitas Langrafe \\ Danilo Martins Torini \\ Antonio Renato Cecconello
}

As rápidas transformações que ocorrem na contemporaneidade requerem mudanças no ambiente educacional. Estas, por sua vez, engendram um novo paradigma de docência universitária. Nesse contexto, as transformações que mais repercutem sobre a prática docente decorrem da exigência de orientar o ensino pela e para a aprendizagem dos estudantes. Mas até que ponto já desenvolvemos as competências pedagógicas requeridas pelo processo de ensino-aprendizagem? Em que medida temos sido capazes de criar ambientes que favoreçam a aprendizagem dos estudantes? No esforço de superarmos visões impressionistas realizamos um levantamento de dados com a aplicação de um questionário. Contamos com 301 respostas válidas e o exercício interpretativo dos dados ajudou a identificar nossos principais desafios enquanto docentes de cursos de graduação e tecnólogos em Administração. O texto evolui da introdução para a descrição dos recursos metodológicos, seguida da descrição e interpretação dos dados, exercício que legitimou os achados e a sinalização de desdobramentos possíveis. Foi identificada a necessidade de soluções estruturais no processo de formação e atualização dos Profissionais que atuam no novo contexto do Ensino Superior.

Palavras chave: Novo paradigma de docência universitária, Docência universitária, Formação pedagógica, Professores do curso de Administração.

The rapid transformations that occur in contemporary times require changes in the educational environment. These, in turn, engender a new paradigm of university teaching. In this context, the transformations that most impact on teaching practice derive from the need to guide teaching by and for students' learning. But to what extent have we developed the pedagogical skills required for the teaching-learning process? To what extent have we been able to create environments that

Texto convidado em Novembro/2019

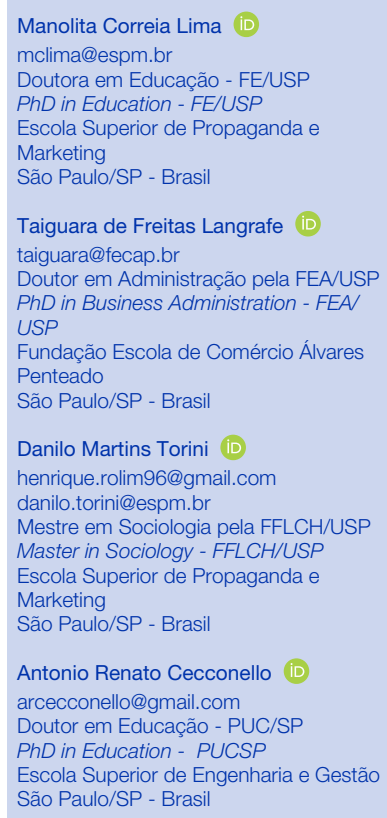


foster student learning? In an effort to overcome impressionist visions we conducted a data survey with the application of a questionnaire. We had 301 valid answers and the interpretive exercise of the data helped to identify our main challenges as undergraduate business administration teachers. The text evolves from the introduction to the description of the methodological resources, followed by the description and interpretation of the data, an exercise that legitimized the findings and the signaling of possible developments. Was identified the need for structural solutions in the formation and actualization process of professionals who perform in the new Higher Education Context.

Keywords: New paradigm of university teaching, University teaching, Pedagogical formation, Business Administration Professors.

\section{Introdução}

Se ensinarmos nossos estudantes de hoje como nós ensinávamos os de ontem, estaremos lhes roubando o futuro.

John Dewey

As rápidas transformações que ocorrem na contemporaneidade requerem mudanças no ambiente educacional, temos fortes chances de estar contribuindo para a formação de jovens que estarão ativos no Século 22 (HARARI, 2018). No contexto das sociedades intensivas de conhecimento, a cristalização de práticas docentes orientadas por lógicas do passado parece descolada dos desafios do presente e do futuro (SORDI, 2019). Isso implica transformações estruturais nas Instituições de Educação Superior (IES) e elas passam, por exemplo, pela redefinição das competências a serem desenvolvidas, redesenhos curriculares, indissociação entre ensino-aprendizagem, redefinição das responsabilidades docentes e discentes etc. Frente ao exposto, não é exagero afirmar que caminhamos na direção de um novo paradigma de docência universitária. (ALMEIDA \& PIMENTA, 2014).

Nesse contexto, o trabalho docente também requer expressivas transformações, possivelmente, a que mais repercute sobre os professores é a exigência de orientar o ensino pela e para a aprendizagem dos estudantes. A intensidade com 
que somos atingidos por esta transformação pode variar, mas se tivermos a intenção de investir no magistério superior, precisamos empreender esforços para desenvolver competências pedagógicas. Há muito tempo a Educação Superior acolhe profissionais que exercem à docência superior tendo a formação acadêmica em determinado campo de conhecimento como critério de seleção. Dependendo do campo de conhecimento, particularmente no âmbito das ciências sociais aplicadas, seleciona-se com base na combinação entre formação acadêmica e experiência profissional. Adota-se a máxima "quem sabe, automaticamente sabe ensinar" (MASETTO, 2003, p.13), enfatizando o ensino de conteúdos, pouco consciente dos desafios implicados na promoção da aprendizagem.

Mas quando levamos em conta que sociedades intensivas de conhecimento caminham em paralelo com sociedades intensivas de aprendizagem, dispor de "competências de ensino" possivelmente será insuficiente. Mas até que ponto desenvolvemos as competências pedagógicas requeridas pelo processo de ensino-aprendizagem? Em que medida temos sido capazes de criar ambientes que favoreçam a aprendizagem? A realização do mestrado e do doutorado garante o desenvolvimento de competências que aproximam ensino da aprendizagem? Em que medida nos sentimos seguros para promover as transformações requeridas pela atividade docente na contemporaneidade? Assumimos o pressuposto de que jamais haverá plena segurança, uma vez que os desafios implicados no processo de ensino-aprendizagem nos levarão a buscar permanentemente recursos didáticos-pedagógicos que nos permitam ampliar as condições que favoreçam a aprendizagem dos estudantes. Possivelmente, a consciência de que o exercício da docência requer o perfil de um profissional polivalente, multifuncional e intelectualmente sofisticado, justifica Sordi (2019) colocar em dúvida a oferta de atividades exclusivamente orientadas para a instrumentalização do docente para um agir pedagógico contemporâneo.

Nesse contexto, em que termos definimos os propósitos do levantamento de dados realizado? No esforço de superarmos visões impressionistas, desejamos contribuir para o mapeamento de nossas práticas pedagógicas (aonde estamos?), identificar nossos principais desafios (diagnóstico) e eles apontarem para nossas necessidades enquanto docentes dos cursos de graduação e tecnólogos em Administração. Com isso, esperamos criar um espaço de reflexão fundamentada e pro- 
positiva na expectativa de pensarmos coletivamente alternativas que nos ajudem a exercer a docência universitária com mais propriedade, em sintonia com os novos desafios que emergem na sociedade contemporânea.

O texto em tela deriva de um exercício interpretativo de dados resultantes de um levantamento realizado por meio da aplicação de um questionário. Iremos contrariar a arquitetura prevalecente nos artigos acadêmicos à medida que escreveremos na primeira pessoa do plural, articulando as lentes teóricas e o exercício que transitará entre descrição, interpretação e reflexão propositiva. Assim sendo, o texto evoluirá desta introdução, para a descrição dos recursos metodológicos mobilizados. Em seguida, a ênfase recairá sobre o exercício descritivo, interpretativo e reflexivo dos dados. Finalmente, reuniremos os achados e sinalizaremos desdobramentos possíveis, além de compartilharmos a literatura consultada na fundamentação teórico-metodológica.

\section{Esclarecimentos de Natureza Metodológica}

Nas últimas edições do Encontro Nacional dos Cursos de Graduação em Administração (EnANGRAD), os organizadores explicitaram crescente preocupação de enriquecer a programação da reunião uma vez que tem atraído um público diversificado em vários aspectos - idade, formação acadêmica, experiência profissional, tempo de dedicação à educação superior, cidade, instituição de origem e reponsabilidades assumidas no curso de Administração etc. - e isso implica em diferentes demandas e diversidade de expectativas. A adesão dos participantes aos temas propostos tem sido tão expressiva que não faltam esforços para identificar as principais demandas da comunidade acadêmica (estudantes, professores, técnicos-educacionais e gestores acadêmicos) e oferecer variado cardápio de atividades. É nesse contexto que a coordenação do tema Ensino, Pesquisa e Formação de Professores se mobilizou para realizar um levantamento capaz de gerar dados que quando interpretados pudessem identificar as necessidades de materiais e atividades que colaborassem com a formação pedagógica dos professores que integram a comunidade docente dos cursos de graduação e tecnólogos em Administração. 
Assim sendo, realizamos um levantamento de dados por meio da elaboração e aplicação de um questionário (FOWLER, 2011) proposto a professores, particularmente aqueles vinculados aos cursos de graduação e tecnólogos em Administração, oferecidos por IES localizadas nas distintas regiões do País. Entre os meses de fevereiro e março de 2019 o instrumento foi elaborado e lapidado com a contribuição de dez professores com reconhecida experiência em pesquisa quantitativa (GÜTHER, 2003). Entre os meses de abril e maio de 2019 o link de acesso à plataforma do SurveyMonkey foi divulgado pela Associação Nacional dos Cursos de Graduação em Administração (ANGRAD). Simultaneamente o convite foi estendido para a rede de contato dos propositores do levantamento. Com a combinação de tais ações atingimos 301 respostas válidas.

O instrumento de coleta reúne 14 questões, que evoluem de perguntas relativas ao perfil do respondente (a), à percepção das responsabilidades que singularizam a prática docente (b), à percepção sobre a proficiência pedagógica desenvolvida até o momento pelo professor (c), à percepção dos desafios envolvidos na prática docente (d), e à percepção sobre o alcance dos objetivos de aprendizagem por parte dos estudantes (e). Concluímos o questionário com a solicitação dos objetivos de aprendizagem de uma das disciplinas que o respondente leciona. Em tese, a maneira pela qual construímos os objetivos revela o tamanho do desafio implicado na proposta e se conscientemente nos orientamos pelo ensino e/ou pela aprendizagem.

Os dados resultantes da aplicação do questionário foram submetidos a um exercício que evoluiu da análise descritiva para a interpretação, finalizando com uma reflexão propositiva. Buscamos estabelecer correlações entre algumas respostas no objetivo de gerar resultados mais robustos (MORAIS, 2010). Há consciência dos limites desse tipo de levantamento, seja no que se refere a apreensão de percepção sobre o que é questionado, seja no diz respeito a variada margem de indução que todo questionário pode gerar (GÜTHER, 2003). No intuito de diminuir tais limitações, primeiramente submetemos o questionário ao crivo de dez experientes professores-pesquisadores nesse tipo de levantamento, e durante o $30^{\circ}$ EnAngrad promovemos uma oficina com a preocupação de discutir os resultados com os interessados, qualificar os dados e refinar a reflexão propositiva. 


\section{Descrição e Interpretação dos Dados}

\section{PERFIL DOS RESPONDENTES: TITULAÇÃO E CURSO QUE LECIONA}

A experiência em pesquisa permite assegurar que quanto mais conhecemos o perfil do respondente, mais é possível significar às respectivas respostas. Isso explica a atenção conferida a este aspecto. Refletindo os critérios de avaliação externa a que os cursos de Graduação estão submetidos, a titulação da grande maioria $(90,3 \%)$ dos respondentes transita entre Mestre $(49,3 \%)$ e Doutor $(41,0 \%)$ (Gráfico1). Números que ultrapassam com folga a Meta 13 do Plano Nacional de Educação (PNE) que trata da titulação dos professores vinculados à Educação Superior - "garantir que pelo menos $75 \%$ dos professores da Educação Superior sejam mestres e 35\%, doutores".

Gráfico 1 Titulação mais recente.

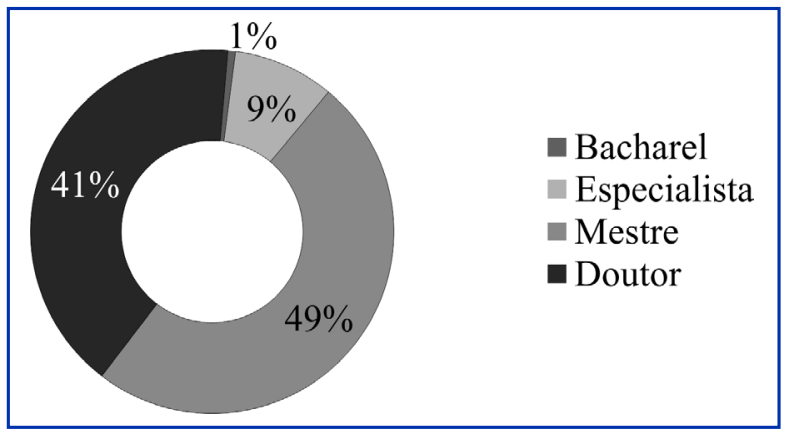

Fonte: Questionário aplicado, 2019.

Considerando os números relativos à titulação dos Professores dos Cursos de Administração discutidos na Oficina de Análise dos Dados do Exame Nacional de Desempenho dos Estudantes (ENADE), oferecida no EnAngrad, edição 2017, constatamos uma evolução nos dados auto declaratórios correspondente a titulação mínima de Mestres nos Cursos de Administração - de 52,7\% em 2009, para 65,6\% em 2012, e 72,7\% em 2015 - e de Doutores - de 9,1\% em 2009, 21\% em 2012, e 25,3\% em 2015 (LANGRAFE, BELTRÃO e BERNDT, 2017). Possivelmente a titulação informada pelos respondentes que integram a nossa amostra ajude a 
entender a multiplicidade de atividades que eles asseguram realizar, simultaneamente, apenas exemplificando: membro do Núcleo Docente Estruturante - NDE $(67,2 \%)$, coordenador de curso $(48,1 \%)$, coordenador de Trabalho de Conclusão de Curso - TCC $(23,4 \%)$, coordenador de extensão $(20,9 \%)$, coordenador do Estágio Supervisionado (18,3\%).

Como era esperado, prevalecem a presença de professores que lecionam disciplinas oferecidas nos cursos de Administração $(83,7 \%)$, secundariamente aparecem Contabilidade/Atuária (22,5\%), Engenharias (13,5\%), Economia (8,4\%), Ciências Sociais $(7,3 \%)$ e Sistemas de Informação (6,7\%). Ainda foram citados outros cursos por cerca de um terço dos respondentes $(29,2 \%)$, revelando a diversidade de áreas de atuação uma vez que no total, 43 cursos foram mencionados.

Gráfico 2 Curso que leciona (atualmente).

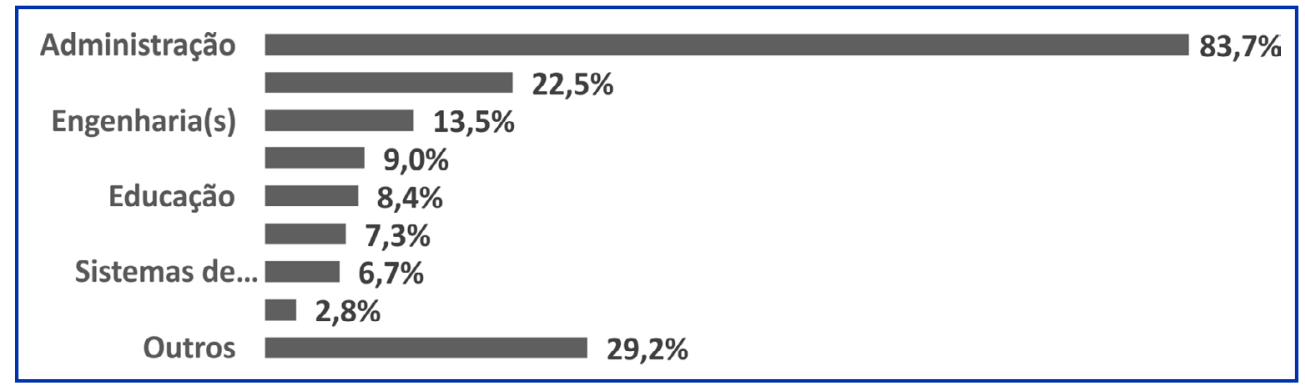

Fonte: Questionário aplicado, 2019.

\section{PERFIL DOS RESPONDENTES: COMBINAÇÃO DA DOCÊNCIA COM OUTRAS ATIVIDADES PROFISSIONAIS}

Em cada dez respondentes, sete $(67,6 \%)$ desempenham outras atividades profissionais além da docência: metade (49,5\%) de forma fixa e 18,1\% esporadicamente. Entre os docentes desses dois grupos, 40,9\% dedicam até dez horas semanais a essas outras atividades e 20,9\% têm dedicação que varia entre 11 a 20 horas semanais. Também é significativo que quase quatro em cada dez respondentes $(38,2 \%)$ afirmem dedicar mais de 20 horas semanais a essas outras atividades profissionais, com prevalência dos que possuem dedicação acima de 30 horas por semana $(24,1 \%)$ (Gráfico 3). Trata-se de expressiva carga de trabalho 
e isso remete a quatro questões: 1) no grupo de respondentes, prevalecem professores-profissionais ou profissionais-professores, com quais implicações para as transformações didático-pedagógicas atualmente requeridas? 2) considerando a carga de trabalho semanal que grande parte dos professores cumpre, questiona-se qual é o tempo reservado para os estudos, particularmente de questões relacionadas à docência? 3) o ensino orientado para a aprendizagem é exigente em tempo, tanto para dedicar às atividades de planejamento, quanto de realização, avaliação da aprendizagem em processo e feedback, como é possível equilibrar tudo isso com tantas e simultâneas demandas profissionais? 4) em que medida isso representa um freio no exigente processo de transformação pedagógica atualmente requerida?

Gráfico 3 Desempenho de atividades estranhas à docência.

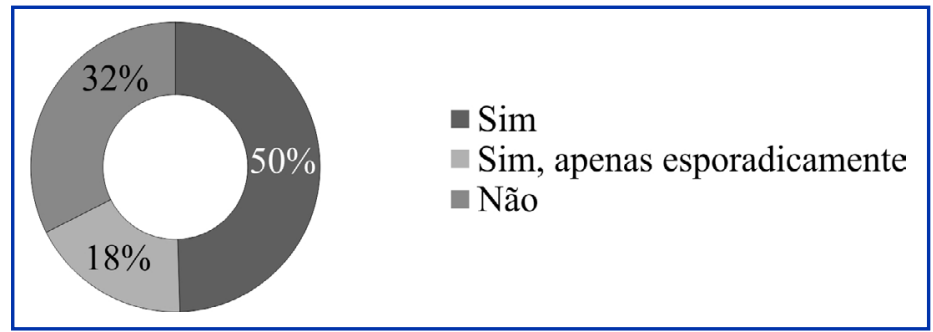

Fonte: Questionário aplicado, 2019.

\section{PERFIL DOS RESPONDENTES: TEMPO DE DEDICAÇÃO À DOCÊNCIA E VÍN- CULOS INSTITUCIONAIS}

Além de uma formação acadêmica admirável (90,3\% são mestres e/ou doutores), o grupo declara acumular expressivo tempo de experiência na docência universitária: cerca de seis em cada dez lecionam há mais de 12 anos; destes, 20,7\% já trabalham há mais de 25 anos como professores nesse nível de ensino. Outros 40,8\% possuem experiência entre 12 a 24 anos, dois em cada dez afirmam, por sua vez, ter experiência de até 11 anos no exercício da docência universitária (Gráfico 4). A formação acadêmica, associada à experiência docente ajuda a explicar o número de coordenadores de curso $(48,1 \%)$ e representantes do NDE $(67,2 \%)$, por exemplo - sabidamente, tratam-se de funções que envolvem responsabilidades voltadas para a estruturação dos cursos de Administração. 
Gráfico 4 Tempo de dedicação à docência universitária.

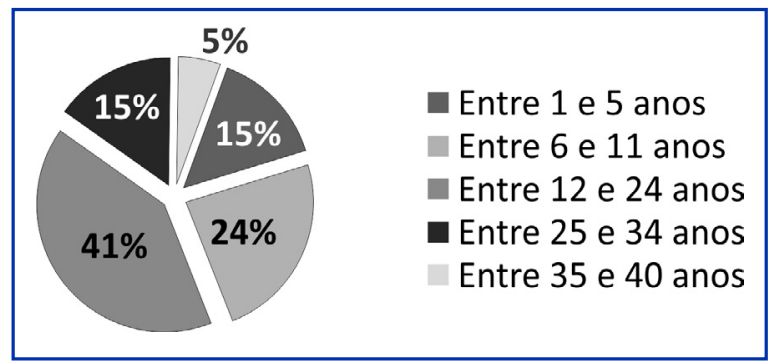

Fonte: Questionário aplicado, 2019.

\section{PERFIL DOS RESPONDENTES: ETAPAS DA TRAJETÓRIA PROFISSIONAL DOCENTE}

Independentemente da geração e do gênero, no curso de nossa trajetória docente vivemos as mesmas etapas? Considerando as etapas vividas, qual é a imagem que projetamos de nós mesmos, enquanto docentes, em cada uma delas? Com o tempo e a experiência docente, tornamo-nos mais competentes e seguros? Mais felizes e realizados? Mais prudentes, conservadores e céticos? Quais são os piores e os melhores anos da docência? Quais são os fatores que contribuem para que o final da trajetória docente seja marcado pela serenidade, pelo conflito e/ou pela desmobilização?

Estas questões merecem ser investigadas porque os resultados conhecidos traduzem parcialmente o contexto em que vivemos. Estamos superando uma visão binária que separa tempo de estudo e trabalho, vivemos cada vez mais, e dificilmente nos aposentaremos. Assim sendo, a curva que Huberman (2000) propõe na busca de traduzir o ciclo de vida de um professor - ingresso, estabilização, diversificação, serenidade / distanciamento, desinvestimento / preparação para a aposentadoria - requer atualização. Consequentemente, ao elaborarmos o instrumento de coleta, não associamos o término do itinerário docente com o fim da trajetória profissional. Acreditamos que os dados relativos à formação acadêmica e à experiência docente ajudam a compreendermos a imagem que os respondentes formam e projetam de si, quando levam em conta o percurso profissional enquanto professores universitários. 
Tabela 1 Trajetória docente e autoimagem.

...sou um Professor que, apesar de ter encontrado um caminho, tem consciência de que a docência requer permanente processo de (auto) $\quad 30 \%$ formação

...sou um Professor seguro, ciente da qualidade de seu próprio trabaIho, realizado, reco-nhecido pelos estudantes e pelos pares

...sou um Professor consciente de ter realizado um bom trabalho, mas que deseja se engajar em novos projetos.

...sou um Professor experiente, comprometido, disposto a compartilhar o que sabe, em busca de boas oportunidades e de reconhecimento

...sou um Professor com pouca experiência, em início de carreira, disposto a explorar experiências que forneçam bases necessárias para uma atuação docente satisfatória

Fonte: Questionário aplicado, 2019.

Reafirmamos, trata-se de um grupo excepcional, enquanto um pouco mais de $60 \%$ se consideram experientes, seguros e conscientes de que realizam um bom trabalho, menos de dez por cento $(9,3 \%)$ estão dando os primeiros passos na direção de uma trajetória profissional docente. Mais de $1 / 4$ (30\%) se veem como um professor que, apesar de ter encontrado um caminho, têm consciência de que a docência requer permanente processo de (auto)formação, aliás, como qualquer atividade profissional! Chama atenção o fato de $22,3 \%$ serem conscientes de ter realizado um bom trabalho, mas almejarem novos projetos, outros desafios. Aponta para um grupo que não reconhece a aposentaria como um fim de um percurso profissional, reafirmando o que argumenta Harari (2018).

Mesmo que os números sejam animadores, suscitam questionamento. Corroborando o que vários autores asseguram, Colet (2009), Soares e Cunha (2010) argumentam que o professor universitário constrói sua identidade docente a partir de vivências pouco estruturadas - na troca com familiares, na observação da prática de antigos professores, na própria experiência autodidata, além das trocas com colegas de profissão e da reação dos estudantes com quem tem oportunidade de trabalhar. Essa percepção é reforçada pelos dados reunidos uma vez que 35,8\% dos 
respondentes afirmam ter alcançado proficiência didático-pedagógica exclusivamente na prática, $17,2 \%$ pela participação a diversos minicursos, palestras, oficinas e workshops, 10,8\% pela participação em uma disciplina dedicada a temas relacionados à didática do ensino superior e 5,7\% se declaram exclusivamente autodidata (apenas 30,4\% afirmam ter investido em cursos de formação em Educação).

Assim sendo, como fomos capazes de desenvolver características de um profissional polivalente, multifuncional, intelectualmente sofisticado (RUIZ et al., 2017)? Se traspusermos esses dados para qualquer outra ocupação, em que medida confiaríamos no desenvolvimento das competências exigidas de um arquiteto, ou de um enfermeiro, quem sabe de um piloto de avião? Até que ponto a naturalização da docência superior seria um entrave à consolidação de um ensino efetivamente orientado para a aprendizagem? Em que medida isso contribui para a desvalorização social dos professores universitários? Não parece curioso que os professores sejam responsabilizados pela crise da educação e, ao mesmo tempo, reconhecidos como a principal alternativa para as soluções dos problemas decorrentes? (RUIZ et al., 2017).

A figura do "professor taxista" é praticamente ausente da amostra. Apesar de 94,0\% atuarem em cursos de graduação em Administração, considerando o número de vínculos de trabalho que possuem, prevalecem aqueles associados a apenas uma IES $(78,7 \%)$ e reduzido número está vinculado a duas (14,3\%), três ou mais instituições (7,0\%). O que pode ajudar a explicar o elevado número de respondentes que declara desempenhar outra atividade profissional, além da docência $(67,6 \%)$, de forma regular $(49,5 \%)$ ou esporádica $(18,1 \%)$, dedicando, para isso, uma carga horária igualmente elevada: 40,9\% até 10 horas semanais, 20,9\% entre 11 e 20 horas semanais, $14,1 \%$ entre 21 e 30 horas semanais e $24,1 \%$ mais de 30 horas semanais.

O crescente número de professores com contrato de dedicação em tempo integral ou parcial é reforçado pela série histórica elaborada por Langrafe, Beltrão e Berndt (2017): 45,4\% em 2009, 66\% em 2012 e 73\% em 2015. Dados que apontam para alguma consolidação dos cursos de Administração, mas que merecem ser aprofundados uma vez que as disciplinas técnicas do currículo do curso de Administração requerem professores com consistente formação acadêmico-pedagógica e vivência prática. 
Gráfico 5 Vínculo profissional dos professores.

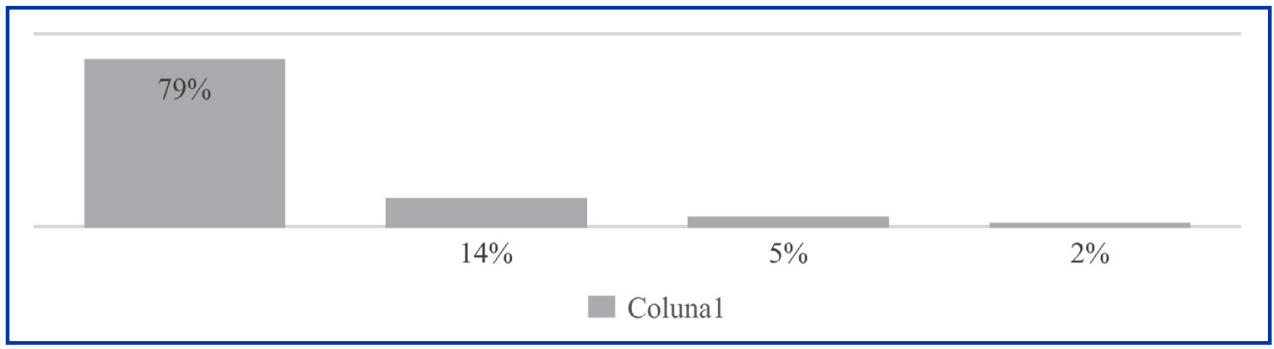

Fonte: Questionário aplicado, 2019.

\section{PERFIL DOS RESPONDENTES: DOCÊNCIA E ATIVIDADES DE ORIENTAÇÃO}

A grande maioria dos participantes leciona em cursos de Graduação (94,0\%). Pelo fato de combinar admirável formação acadêmica, experiência com atividades profissionais além da docência, um pouco mais da metade (54\%) trabalha simultaneamente na pós-Graduação lato sensu. Um grupo expressivamente menor $(15,8 \%)$ declara lecionar em programas de pós-graduação stricto sensu - praticamente o mesmo grupo que assegura ser editor de revista científica (16,5\%). Contudo, mais da metade $(66,3 \%)$ informa dedicar-se a atividades que envolvem pesquisa e publicação, um pouco menos da metade $(45,4 \%)$ afirma elaborar pareceres de trabaIhos submetidos a congressos e revistas acadêmicas, número quase equivalente $(44,3 \%)$ colabora na organização de reuniões acadêmicas, e um número menor $(36,6 \%)$ integra grupos de pesquisa cadastrados no CNPq.

No que diz respeito às atividades tipicamente didático-pedagógicas, uma vez que envolvem competência para orientar, quase oito, em cada dez professores, sustentam orientar Trabalhos de Conclusão de Curso (TCCs) de Graduação, seguidos dos que orientam projetos de Iniciação Científica (45,9\%), TCCs de Especialização/MBAs $(42,4 \%)$ e Estágio Supervisionado (35,5\%). Levando em conta que apenas $16 \%$ sinalizam lecionar em programas de pós-graduação stricto sensu, parece curioso que 18,3\% assegurem orientar Dissertações! Além disso, 26,6\% asseveram ter experiência com atividades que envolvem tutoria. Considerando que a grande maioria leciona em cursos de Administração (90,4\%), não surpreende que $20,0 \%$ declarem apoiar a realização de projetos de consultoria desenvolvidos no âmbito das Agências Experimentais, a exemplo da Empresa Jr. 
Gráfico 6 Desenvolvimento de atividades de orientação.

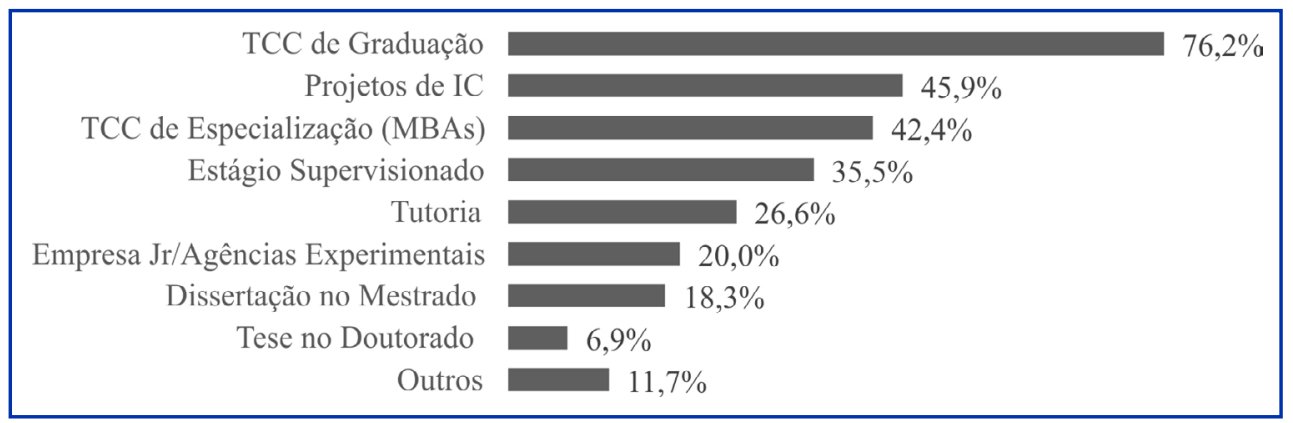

Fonte: Questionário aplicado, 2019.

A profissão acadêmica tem ganhado mais complexidade, por um lado temos cada vez mais consciência de que o ambiente de aprendizagem, seja ele virtual, presencial ou híbrido, funciona como um ecossistema, um local de interdependências em que o trabalho colaborativo é imprescindível; por outro lado sabemos que a prática acadêmica pressupõe a conciliação entre múltiplas atividades, dentro e fora do ambiente educacional e isso tem sido levado ao extremo com o produtivismo. Além dos crescentes desafios da docência, espera-se êxito na pesquisa e publicação (participar de rede internacional de pesquisadores, integrar grupo de pesquisa interinstitucional; ser favorecido com bolsa de pesquisa concedida por prestigiosa agência de fomento, desenvolver e realizar projeto de pesquisa, orientar jovens pesquisadores; elaborar artigos, submeter a congressos e revistas, publicar em revistas de alto impacto; elaborar pareceres; organizar reuniões acadêmicas, participar de congressos; ser (co)editor de revista científica, participar de comitês de toda ordem etc.); na extensão e prestação de serviço (desenvolver e realizar projetos de extensão; avaliar e divulgar os resultados pedagógicos, sociais e econômicos alcançados); sem falar na gestão acadêmica (ser membro do NDE, coordenar cursos e programas variados - iniciação científica, estágio supervisionado, trabalho de conclusão de curso, trabalhos integrados, programa de extensão etc.). A metáfora "professor bombril" traduz a hiperatividade a que esse profissional está submetido (ALCADIPANI, 2005). 


\section{PERFIL DOS RESPONDENTES: GESTÃO ACADÊMICA ASSOCIADA À PESQUI- SA E PUBLICAÇÃO}

"No contexto atual do mundo do trabalho, [...] observa -se [...] a defesa entusiasmada da polivalência, entendida como atributo do trabalhador contemporâneo, adaptado a contextos diversos e possuidor de competências múltiplas que Ihe permitem atuar em diferentes postos de trabalho, agregando eficiência e aumento da produtividade" (RUIZ et al., 2017, p.1193). No ambiente educacional isso não é exceção! Nosso seleto grupo de respondentes parece ter desenvolvido competências múltiplas que os habilitam a combinar atividades cuja realização transita entre ensino, pesquisa, extensão e gestão acadêmica. No que se refere às atividades ligadas à gestão acadêmica, 67,2\% declaram ser membros do NDE de cursos em que lecionam e quase metade $(48,1 \%)$ é coordenador de curso. Cerca de um quarto $(23,4 \%)$ coordenam TCC, seguidos daqueles que coordenam programas de Extensão (20,9\%), Estágio Supervisionado (18,3\%) e Programa de Iniciação Científica (8,1\%).

No que diz respeito às demais atividades exercidas nas IES em que trabaIham, quase sete, em cada dez professores, dizem se dedicar à pesquisa e publicação $(66,3 \%)$, seguidos dos que trabalham com atividades de extensão $(49,5 \%)$, e dos que desenvolvem pareceres para trabalhos inscritos em congressos e/ou revistas científicas $(45,4 \%)$, contribuem na organização de reuniões acadêmicas $(44,3 \%)$ e participam de grupos de pesquisa cadastrados no $\mathrm{CNPq}(36,6 \%)$.

Tabela 2 Desenvolvimento de atividades de pesquisa, extensão e gestão acadêmica.

\begin{tabular}{rc} 
Pesquisa e publicação & $\mathbf{6 6 , 3 \%}$ \\
Atividades de extensão & $\mathbf{4 9 , 5 \%}$ \\
Parecerista em congresso e/ou revistas acadêmicas & $\mathbf{4 5 , 4 \%}$ \\
Organização de reuniões acadêmicas & $\mathbf{4 4 , 3 \%}$ \\
Grupo de pesquisa cadastrado no CNPq & $\mathbf{3 6 , 6 \%}$ \\
Atividades de consultoria & $\mathbf{3 1 , 5 \%}$ \\
\hline Avaliação de cursos e IES (INEP/MEC) & $\mathbf{1 8 , 7 \%}$ \\
\hline Editor Científico de Revista Acadêmica & $\mathbf{1 6 , 5 \%}$ \\
\hline
\end{tabular}

Fonte: Questionário aplicado, 2019. 
Como é possível uma categoria profissional realizar com distinção essa diversidade impressionante de atividades, simultaneamente? Até que ponto o mestrado e o doutorado são capazes de desenvolver competências tão diversas, complexas, exigentes em tempo e dedicação?

\section{RESPONSABILIDADES TÍPICAS DA DOCÊNCIA}

Quando cursos e IES são pressionados a contribuir para desenvolver múltiplas competências e para isso orientar o ensino para a aprendizagem, as responsabilidades docentes têm sido não apenas ampliadas, mas elas têm ganhado em complexidade (SORDI, 2019). Contudo, se considerarmos a literatura nacional e internacional sobre a contribuição do mestrado e do doutorado para a formação do professor universitário perceberemos que há um consenso de que ela tem sido particularmente modesta. Poucos autores se propõem a estabelecer uma relação virtuosa entre formação doutoral e docência superior, Nicole Rege Colet (2009) não é exceção. Considerando a crescente complexidade do trabalho e as caraterísticas do mercado laboral para doutores, particularmente entre os países da Europa ocidental, a autora identifica a existência de um movimento em defesa de redesenhos curriculares visando influir sobre a diversificação das competências dos doutorandos na tentativa de formar um profissional polivalente. Dessa forma, espera-se influir sobre a elevação das possibilidades de inserção dos doutores no mundo do trabalho. É nesse contexto que a defesa da profissionalização dos professores ganha espaço em alguns cursos de doutorado, particularmente localizados em instituições na Bélgica, Suíça e França (COLET, 2009).

\section{PERCEPÇÕES SOBRE AS RESPONSABILIDADES DOCENTES}

A maioria dos professores considera como sendo de sua responsabilidade as atividades de planejamento e curadoria das referências de leitura (92,0\%), a diversificação dos recursos pedagógicos (91,4\%), e a concepção do processo de avaliação da aprendizagem (91,4\%). Observa-se que há menor consenso quanto às responsabilidades associadas ao planejamento de atividades de verificação de leitura $(74,8 \%)$ (por desconhecer?), considerar os interesses dos estudantes no planejamento e desenvolvimento da disciplina $(77,7 \%)$ (por discordar?), discutir o planejamento do ensino-aprendizagem com os estudantes $(79,7 \%)$ (mas, como re- 
conhecê-los sujeitos da própria aprendizagem?), e planejar a oferta de feedback construtivo (86,4\%) (como oportunizar a autorregulação aos estudantes?). Cabe salientar que, sobretudo nos itens relativos à verificação de leitura, oferta de feedback e discussão do planejamento, há uma parcela (de até 5,3\%) que sequer considera essas atividades como sendo de sua responsabilidade.

Figura 1 Percepção das responsabilidades Docentes.

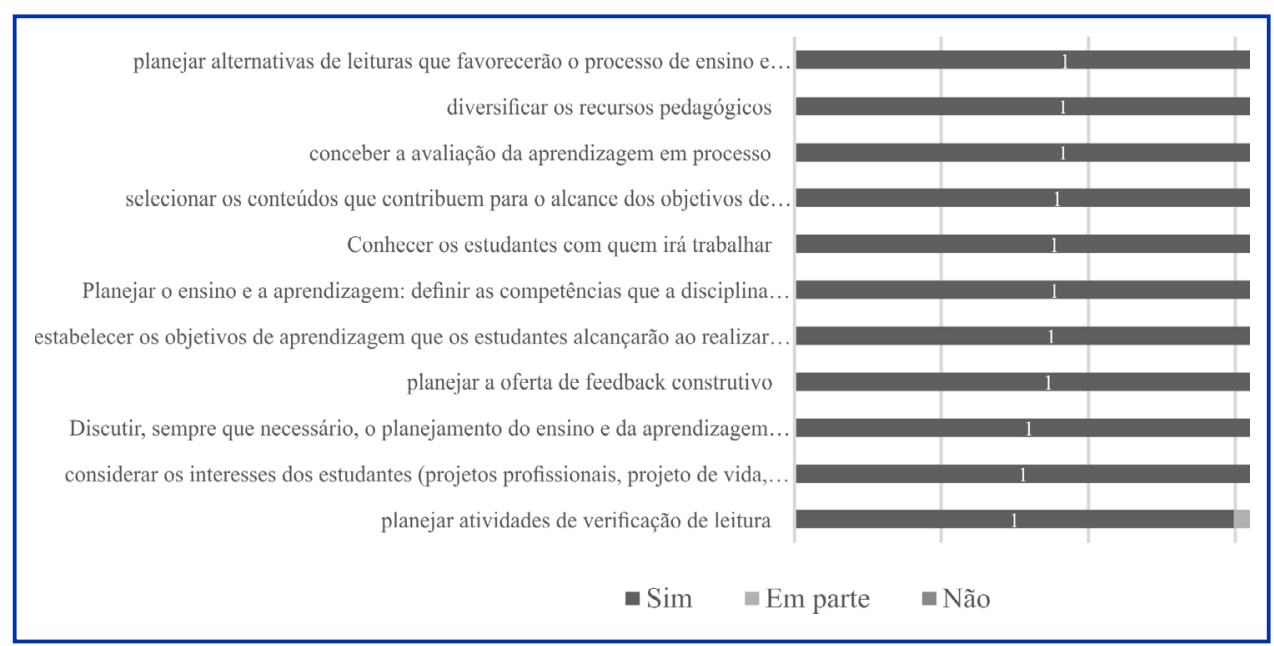

Fonte: Questionário aplicado, 2019.

O ensino orientado para a aprendizagem pressupõe que o professor assuma múltiplas responsabilidades, e elas requerem diversas competências. Por isso mesmo, a literatura tem utilizado distintos conceitos ao se referir ao professor: educador, tutor, mentor, mediador, orientador, facilitador, design educacional, instrutor, curador de conteúdos, influenciador digital etc (LIMA, SANTOS, TORINI, 2020).

\section{PERCEPÇÕES SOBRE A PROFICIÊNCIA PEDAGÓGICA}

Quando se considera a complexidade das responsabilidades que recaem sobre os professores universitários, saber que a formação didático-pedagógica de quase $3 / 4$ resulta exclusivamente de sua prática docente $(35,8 \%)$, de sua participação em atividades pontuais (minicursos, palestras, oficinas e workshops) que requerem reduzida dedicação em tempo $(17,2 \%)$, de sua participação em uma disciplina 
que aborda temas relacionados à didática na educação superior (10,8\%) e de seu autodidatismo (5,7\%), é impossível permanecermos indiferentes. Ao mesmo tempo, parece intrigante que $100 \%$ se revelem interessados por questões relacionadas ao processo de ensino e aprendizagem, mas, simultaneamente, 42 afirmem não haver qualquer interesse pelos resultados desse levantamento. Possivelmente, a titulação da grande maioria - Mestre (49,3\%) e Doutor (41,0\%) - confira relativa tranquilidade entre os respondentes, mas isso seria suficiente? No momento, parece que não!

Figura 2 As competências didático-pedagógicas resultam, principalmente.

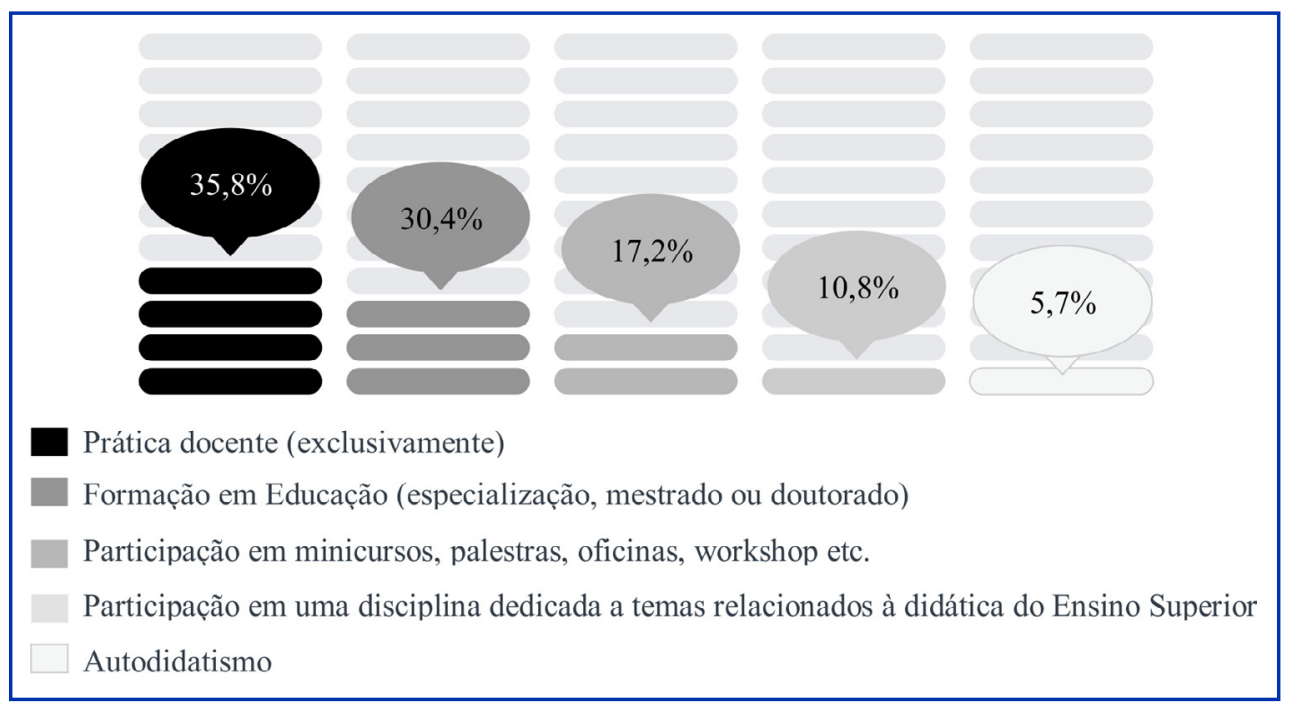

Fonte: Questionário aplicado, 2019.

Considerando uma lista de atividades didático-pedagógica descritas no questionário aplicado, aquelas em que os professores se consideram mais proficientes estão as de estabelecer os objetivos de aprendizagem $(81,4 \%)$ e as competências que a disciplina ministrada contribuirá para desenvolver (78,1\%). Mas, sabidamente, as competências que determinado curso se compromete a colaborar para desenvolver estão definidas no Projeto Pedagógico do Curso, possivelmente os professores não tenham autonomia para modifica-las. Curiosamente, os verbos utilizados para comunicar os objetivos de aprendizagem estão predominantemente associados a atividades de ensino, apenas secundariamente remetem aos desa- 
fios da aprendizagem! Em seguida, quase três quartos $(74,1 \%)$ sinalizam a habilidade de trabalhar com abordagens multidisciplinares, e um número discretamente menor $(73,8 \%)$ de mobilizar os estudantes para a aprendizagem e de realizar feedback $(73,4 \%)$ - desafios conhecidamente exigentes, dificilmente ultrapassados de forma espontânea.

Por outro lado, em quatro atividades apenas metade dos respondentes declara considerar-se como proficiente: conhecer e explorar pedagogicamente dados relativos aos estilos de aprendizagem dos estudantes (49,5\% e 51,8\%, respectivamente), explorar ferramentas de verificação de leitura $(45,9 \%)$ e desenvolver protocolos e rubricas de avaliação da aprendizagem (47,2\%), ou seja, atividades docentes que contribuem sobremaneira para o engajamento dos estudantes (a tabela 3 reúne a média ponderada da frequências de notas (1 a 5), que poderia ser interpretada como a percepção dos respondentes sobre as respectivas proficiências).

Tabela 3 Nível de proficiência pedagógica percebida.

$\begin{array}{cc}\text { Nota } & \% \\ \text { média } & \text { Média }\end{array}$

Sei estabelecer os objetivos de aprendizagem que os estudantes alcançarão ao realizar a disciplina

\section{$4,11 \quad 82,3 \%$}

Sei definir as competências que a disciplina que leciono contribuirá para desenvolver

$4,08 \quad 81,7 \%$

Sei trabalhar com abordagens multidisciplinares $\quad 4,02 \quad 80,5 \%$

Sei realizar feedback construtivo $\quad 3,94 \quad 78,7 \%$

Sei mobilizar os estudantes para a aprendizagem $\quad 3,93 \quad 78,7 \%$

Sei explorar métodos, estratégias e ferramentas que favorecem o processo de ensino orientado pela aprendizagem

$3,90 \quad 78,0 \%$

Sei explorar a avaliação como um recurso que favorece a aprendizagem

\section{$3,84 \quad 76,7 \%$}

Sei planejar o ensino orientado pela aprendizagem

$3,82 \quad 76,4 \%$

Sei explorar recursos tecnológicos (TIC) que favorecem o processo de ensino orientado pela aprendizagem 
Sei explorar bases de dados que favorecem o processo de ensino orientado pela a aprendizagem

$3,63 \quad 68,4 \%$

Sei explorar pedagogicamente os dados resultantes de um questionário que revele os estilos de aprendizagem dos es$3,42 \quad 68,1 \%$ tudantes

Conheço instrumentos, a exemplo de questionários, cujos resultados revelam os estilos de aprendizagem dos estudantes

Sei explorar ferramentas que me permitem verificar a dedicação dos estudantes às atividades solicitadas antes das $3,40 \quad 68,0 \%$ aulas

Sei desenvolver protocolos de avaliação da aprendizagem $3,40 \quad 67,9 \%$

Fonte: Questionário aplicado, 2019.

Por que se espera que os professores consigam influir sobre o interesse dos estudantes pelos estudos? Na sociedade do acesso, a produção e circulação de dados e informação é intensa. Nesse contexto, a pertinência da educação superior reside em contribuir para que estudantes sejam capazes de transformar dados e informações em conhecimento. Na medida em que algumas IES, cursos e professores insistem em trabalhar com estoques de conhecimento (valorizando a ciência como produto), a experiência formativa perde em significado, e os estudantes, expostos a inúmeras fontes de dados e informações, não conseguem imprimir relevância às experiências proporcionadas pelo ambiente educacional.

Apesar da riqueza de informação gerar a pobreza de atenção (Herbert Simon), de todas as funções internas que ajudam a imprimir significado ao mundo exterior, a atenção é a mais importante, na medida em que ela permite reconhecermos o que é significativo e relevante, e produzirmos uma espécie de caos organizado (SWICKER, 2017). Transitamos entre o espaço físico, o mental, e o virtual, a disputa pela atenção está presente em todos eles e o tempo das pessoas é um recurso escasso, intensamente disputado! A natureza finita do tempo implica afirmar que no mundo da "web atenção" tudo está em concorrência com tudo. Assim sendo, como concorrer com possibilidades variadas, interessantes e efêmeras? Como atrair a atenção dos estudantes? 
Vários autores têm contribuído para a discussão desta questão e propõem encaminhamentos distintos, apesar de identificarmos algumas convergências: Philippe Perrenoud argumenta a importância de conhecer o estudante para conseguir estabelecer uma relação pedagógica construtiva com ele; Frederick Irving Herzberg defende o valor de se trabalhar a motivação, George Kuh pondera a relevância de promover o engajamento, Alexander Astin justifica a centralidade da geração de envolvimento, Bernard Charlot argumenta o poder da mobilização, e Alain Coulon discute a necessidade de comprometer o estudante - autores e leituras imperdíveis!

\section{PERCEPÇÃO ACERCA DA APRENDIZAGEM DOS ESTUDANTES}

Apesar de todos os desafios pedagógicos antes apontados, quase sete, em cada 10 professores $(67,8 \%)$, acreditam que, ao concluir um semestre, os estudantes tenham atingido, em geral, até $75 \%$ dos objetivos de aprendizagem da disciplina (sublinha-se que não estamos nos referindo a conteúdos). Outros $26,7 \%$ estão convencidos de que essa faixa variou de $25 \%$ a $50 \%$ de atingimento dos objetivos. As parcelas que acreditam que os estudantes atingiram $100 \%$ dos objetivos (3,3\%) e aquela que pensa que esse percentual foi abaixo de $25 \%$ $(2,3 \%)$ são residuais.

Tabela 4 Alcance médio dos objetivos de aprendizagem.

\begin{tabular}{lccc} 
& Respondentes & $\%$ & Ponderação \\
\hline a) Menos de 25\% & 7 & $2,3 \%$ & $12,5 \%$ \\
\hline b) Entre $25 \%$ e $50 \%$ & 80 & $26,6 \%$ & $37,5 \%$ \\
c) Até $75 \%$ & 204 & $67,8 \%$ & $62,5 \%$ \\
d) $100 \%$ & 10 & $3,3 \%$ & $100,0 \%$ \\
Total & $\mathbf{3 0 1}$ & $\mathbf{1 0 0 , 0} \%$ & $\mathbf{5 5 , 9} \%$ \\
\hline
\end{tabular}

Fonte: Questionário aplicado, 2019.

Esses resultados remetem a algumas questões: em meio a tantos compromissos profissionais, dentro e fora do ambiente educacional, em que medida a avaliação da aprendizagem é realizada processualmente? Ao ser realizada, até que ponto 
é capaz de reunir indícios / evidências que sustentam em que medida os estudantes alcançaram os objetivos de aprendizagem? Lembrando que o terceiro maior desafio dos respondentes é mobilizar os estudantes para a aprendizagem, estamos de fato engajando os estudantes nos estudos? Estamos conseguindo formular objetivos de aprendizagem condizentes com as competências que a disciplina que ministramos se compromete a colaborar para desenvolver?

Há décadas se sabe que a âncora de qualquer Plano de Ensino e Aprendizagem (PEA) é a definição dos objetivos educacionais justificadores da disciplina. São eles que determinam os conteúdos disciplinares (ementa), a escolha dos recursos pedagógicos ajustados aos desafios da aprendizagem (método, estratégias, técnicas, ferramentas), a construção do processo de avaliação da aprendizagem (envolvendo feedback), a definição da bibliografia básica e complementar etc.

A taxonomia dos objetivos educacionais (ou de aprendizagem), proposta por Benjamin Bloom (1972), considerou a existência de três domínios: o cognitivo, o afetivo e o psicomotor. Ao aprofundar o primeiro deles (o cognitivo), o autor estabeleceu seis níveis de aprendizagem - conhecimento, compreensão, aplicação, análise, síntese e avaliação - e quando atualizados, esses níveis sofreram dois ajustes: passaram a ser expressos com o uso de verbos e a criatividade substituiu a síntese (FERRAZ; BELHOT, 2010). Desde então, os objetivos educacionais derivam de seis verbos que transitam entre o pensamento de ordem inferior e o pensamento de ordem superior, por isso mesmo remetem a níveis crescentes de complexidade.

Isso merece ser levado em conta ao se planejar, realizar e avaliar os resultados de uma disciplina, de um módulo e/ou de uma atividade (a exemplo de uma aula), particularmente ao estabelecer os objetivos educacionais. Algumas questões podem nos ajudar a refletir sobre o que se deseja chamar atenção: ao definirmos os objetivos de uma disciplina, levamos em conta o ensino ou a aprendizagem? Ao definir os objetivos de aprendizagem, estamos primando pelo pensamento de ordem superior ou inferior? Qual é a repercussão disso sobre a relevância do curso em geral, a disciplina em particular, e para a formação acadêmica do estudante? 
Quadro 1 Exemplo: definição de objetivos educacionais (ou de aprendizagem).

EXEMPLO

1

\section{Disciplina: Planejamento e Controle da Produção Módulo: Previsão de Vendas}

Ao final do Módulo "Previsão de Vendas", os estudantes deverão ser capazes de:

- LEMBRAR as três hipóteses de previsão e LISTAR os padrões típicos de comportamento de dados históricos, reproduzindo-os na realização de exercícios teóricos, envolvendo os nomes das técnicas de previsão mais utilizadas em processos estacionários, com tendência e com sazonalidade.

- ENTENDER as diferenças entre as técnicas existentes, comparando cada uma delas com as diferentes hipóteses e padrão de dados.

- ESCOLHER e APLICAR uma das técnicas, implementando um programa específico ou utilizando um aplicativo disponivel no mercado.

- ANALISAR as diferentes medidas de erro, diferenciando-as, atribuindo significados de importância e entendendo em quais circunstâncias cada uma delas é mais adequada.

- Avaliar os resultados obtidos por meio do emprego da técnica de previsão, estimando o impacto da acuracidade e das incertezas associadas a todo o processo.

FONTE: FERRAZ, Ana P. C. Marcheti; BELHOT, Renato V. Taxonomia de Bloom: revisão teórica e apresentação das adequações do instrumento para definição de objetivos instrucionais. Gestão\&Produção. São Carlos, v. 17, n. 2, 2010

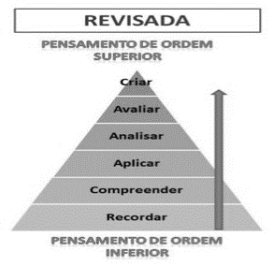

\section{Quadro 2 Exemplo: objetivos educacionais - ênfase no ensino e ênfase na apren-}

\section{dizagem ${ }^{1}$.}

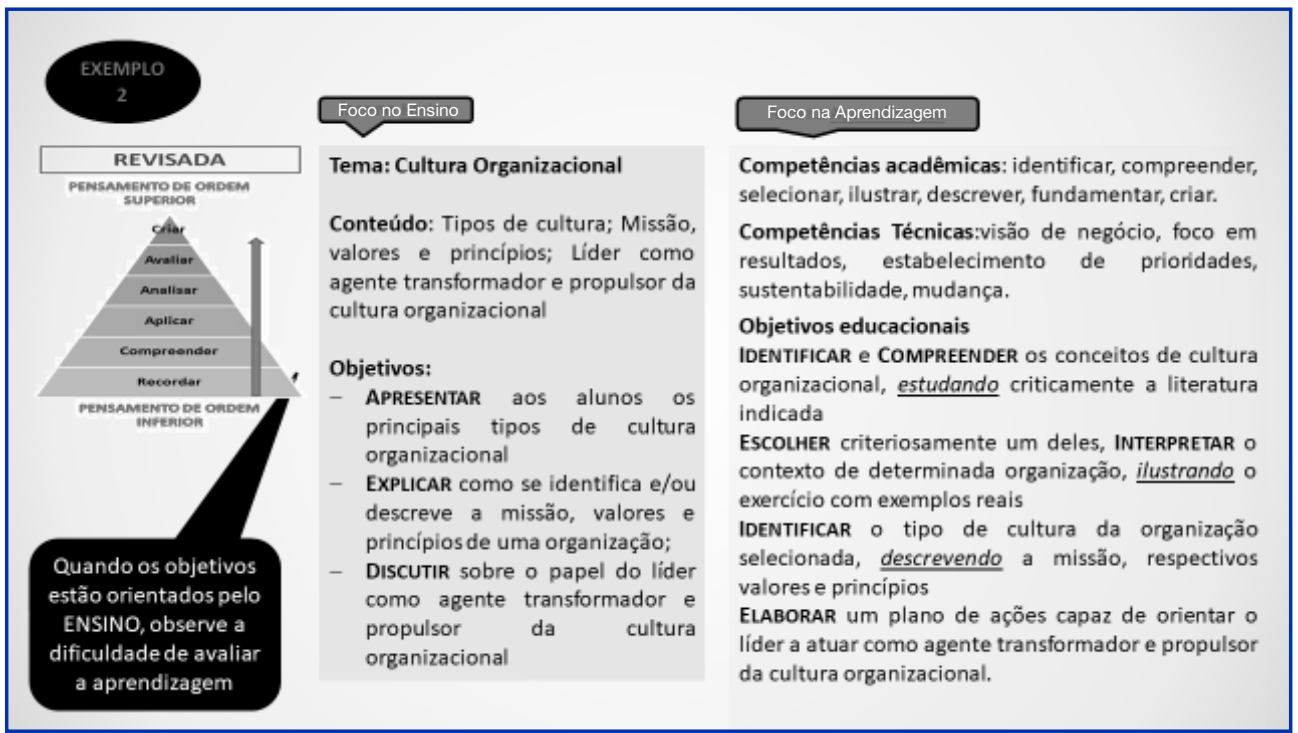

1 Como exemplos, os verbos 'comparar', utilizado nas dimensões Entender, Analisar e Avaliar e 'distinguir', sob as dimensões Lembrar, Entender e Analisar. 
Para uma classificação inicial dos verbos identificados nos objetivos educacionais registrados pelos respondentes, tomando como referência a disciplina mais representativa de sua prática docente, foi utilizada uma base referencial de 127 verbos (alguns aparecendo em mais de uma ordem² de pensamento), distribuídos nos seis domínios cognitivos antes mencionados (Tabela 5).

Tabela 5 Frequência de verbos por domínio cognitivo e ordem (base referencial).

\begin{tabular}{|lrcrc}
\hline \multicolumn{1}{|c}{ Ordem de pensamento } & \multicolumn{2}{c}{ Inferior } & \multicolumn{2}{c}{ Superior } \\
\hline \multicolumn{1}{c}{ Domínio cognitivo } & $\%$ & $\%$ Acum. & $\%$ & $\%$ Acum. \\
\hline $\mathbf{6}$ Criar & $15,0 \%$ & $100,0 \%$ & $26,0 \%$ & $100,0 \%$ \\
\hline $\mathbf{5}$ Avaliar & $10,2 \%$ & $85,0 \%$ & $19,7 \%$ & $74,0 \%$ \\
\hline $\mathbf{4}$ Analisar & $16,5 \%$ & $74,8 \%$ & $16,5 \%$ & $54,3 \%$ \\
\hline $\mathbf{3}$ Aplicar & $21,3 \%$ & $58,3 \%$ & $16,5 \%$ & $37,8 \%$ \\
\hline $\mathbf{2}$ Entender & $21,3 \%$ & $37,0 \%$ & $10,2 \%$ & $21,3 \%$ \\
\hline 1 Lembrar & $15,7 \%$ & $15,7 \%$ & $11,0 \%$ & $11,0 \%$ \\
\hline Total da base & $100,0 \%$ & & $100,0 \%$ & \\
\hline
\end{tabular}

Fonte: Questionário aplicado, 2019.

À luz do que recorrentemente nomeamos de Taxonomia de Bloom, é possível afirmar que o resultado da análise dos objetivos educacionais informados pelos respondentes ratifica a prevalência de uso de verbos que reforçam a cultura pedagógica orientada para o ensino, em detrimento de verbos que reforçam o compromisso com a aprendizagem. A Figura 9 reúne dados que consolidam a distribuição de objetivos educacionais informados pelos respondentes.

2 Em função da dificuldade em se medir o grau de aprendizagem, vários destes verbos não tem seu uso recomendado na elaboração de objetivos de aprendizagem. Como exemplo, entre os 79 verbos constam: atuar, entender, expressar, fortalecer, observar, vivenciar. 
Figura 2 Objetivos educacionais classificados por viés ensino e/ou aprendizagem.

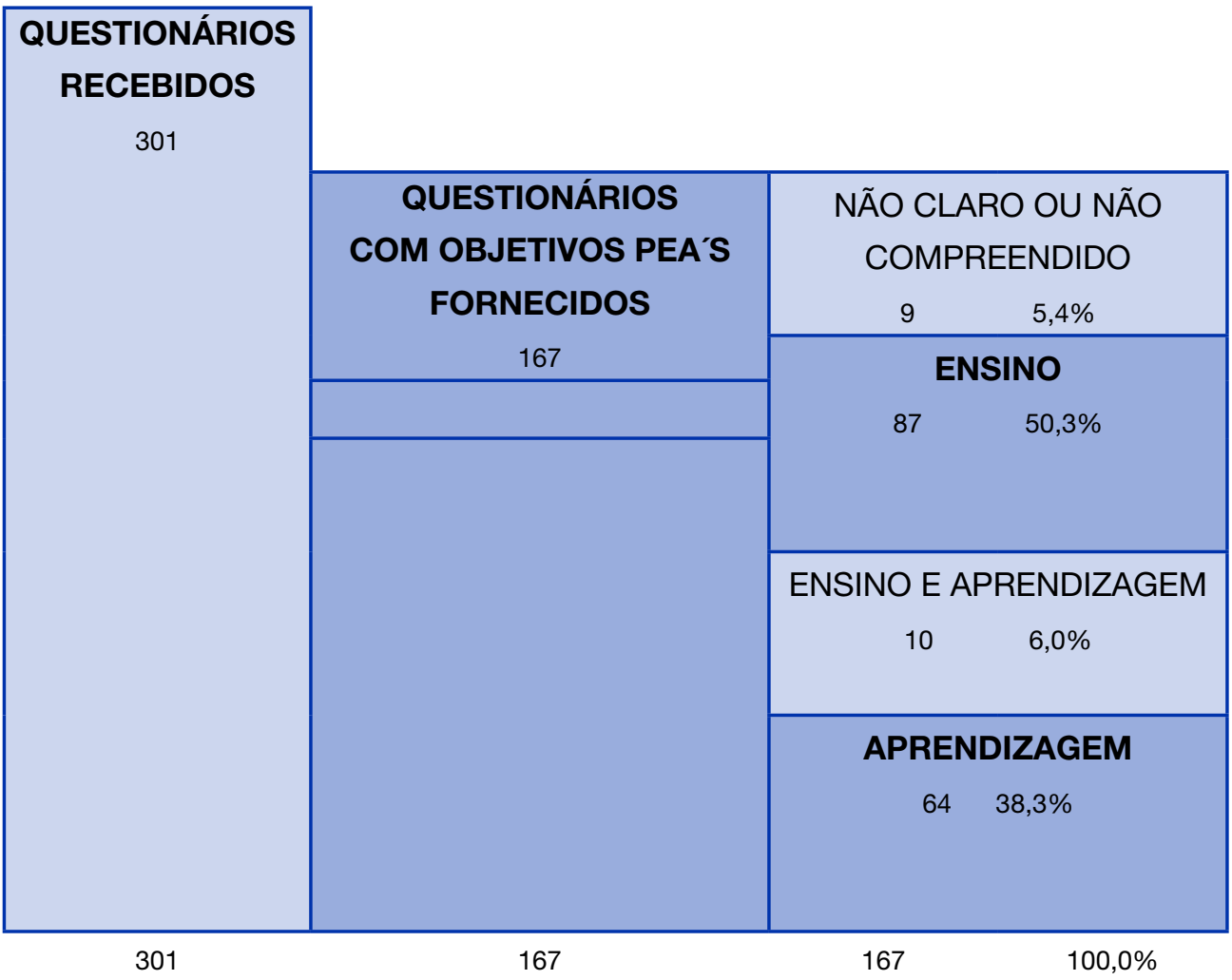

Fonte: Questionário aplicado, 2019.

Dos 301 questionários válidos, apenas 167 respondentes registraram os objetivos educacionais. Destes, enquanto 38,3\% (64) utilizam verbos alinhados ao desafio da aprendizagem, 50,3\% (84) preservam objetivos orientados para a atividade de ensino. Os demais apresentam redação dupla, ora enfatizam o ensino, ora destacam a aprendizagem (6,0\%) ou a redação dificulta a compreensão do enunciado $(5,4 \%)$. A leitura dos 64 (38,3\%) objetivos educacionais alinhados à aprendizagem permitiu a identificação e classificação de 335 verbos, dos quais, apenas 256 puderam ser associados a taxonomia dos objetivos educacionais de Bloom. Isso equivale a afirmar que 79 verbos $^{3}$ não integram a base adotada.

3 Em virtude de vários verbos constarem em mais de uma dimensão cognitiva, optou-se pela análise com relações de verbos distintas e alocações em duas tabelas extremas. 
Tabela 6 Verbos identificados por nível de domínio (ordem de pensamento) ${ }^{4}$

\begin{tabular}{|lcccccc}
\hline \multicolumn{1}{|c}{ Ordem de pensamento } & \multicolumn{3}{c}{ Inferior } & \multicolumn{3}{c|}{ Superior } \\
\hline \multicolumn{1}{|c}{ Dimensão cognitiva } & Freq. & $\%$ & $\begin{array}{c}\text { Acum } \\
\text { Inf. } \%\end{array}$ & Freq. & $\%$ & $\begin{array}{c}\text { Acum } \\
\text { Sup. \% }\end{array}$ \\
\hline 6 Criar & 15 & $5,9 \%$ & $100,0 \%$ & 35 & $13,7 \%$ & $100,0 \%$ \\
\hline 5 Avaliar & 23 & $9,0 \%$ & $94,1 \%$ & 40 & $15,6 \%$ & $86,3 \%$ \\
\hline 4 Analisar & 37 & $14,5 \%$ & $85,2 \%$ & 74 & $28,9 \%$ & $70,7 \%$ \\
\hline 3 Aplicar & 39 & $15,2 \%$ & $70,7 \%$ & 26 & $10,2 \%$ & $41,8 \%$ \\
\hline 2 Entender & 75 & $29,3 \%$ & $55,5 \%$ & 77 & $30,1 \%$ & $31,6 \%$ \\
\hline 1 Lembrar & 67 & $26,2 \%$ & $26,2 \%$ & 4 & $1,6 \%$ & $1,6 \%$ \\
\hline Total da base & 256 & $100,0 \%$ & & 256 & $100,0 \%$ & \\
\hline Verbos identificados & 335 & & & & & \\
\hline Não identificados & 79 & & & & & \\
\hline
\end{tabular}

Fonte: Questionário aplicado, 2019.

\section{DESAFIOS ASSOCIADOS À PRÁTICA DOCENTE ${ }^{5}$}

Dentre os maiores desafios enfrentados pelos respondentes em sua prática docente (Tabela 5), está o de dispor de tempo para se dedicar ao estudo de questões pedagógicas $(69,5 \%)$, percepção compreensível quando consideramos a carga de trabalho semanal sinalizada por grande parte dos respondentes. O segundo maior desafio se refere às condições de trabalho à medida que os professores se ressentem de trabalhar com um grande número de estudantes por turma $(67,7 \%)$, seguido por orientar o ensino pela aprendizagem ${ }^{6}(66,6 \%)$, e trabalhar com turmas muito heterogêneas em repertório (65,6\%), possivelmente, por isso mesmo, 2/3 declarem ter dificuldade de mobilizar os estudantes para a aprendizagem $(66,5 \%)$.

Por outro lado, na percepção dos professores, constituem pontos menos desafiadores realizar feedback (54,8\%), estabelecer diálogo construtivo com os estu-

4 Média ponderada das notas auto atribuídas pelos respondentes versus respectivas frequências.

5 O desafio centrado em orientar o ensino pela aprendizagem envolve questões institucionais que não raro estão acima da decisão e do esforço pessoal do professor.

6 O artigo n.66 da Lei de Diretrizes e Bases da Educação Nacional (LDB, 1996) prevê que "a preparação (sic) para o exercício do magistério superior far-se-á em nível de pós-graduação, prioritariamente em programas de mestrado e doutorado". 
dantes $(54,8 \%)$, adequar os conteúdos aos objetivos de aprendizagem da disciplina $(54,4 \%)$, argumentar a relevância da disciplina $(54,3 \%)$ e definir os objetivos de aprendizagem da disciplina (50,8\%). Curiosamente, todos eles contribuem de forma direta sobre a mobilização dos estudantes para a aprendizagem!

Em texto assinado por Vasconcellos e Sordi (2016), provocativamente intitulado de Formar professores universitários: tarefa (im)possível?, as autoras chamam atenção para a "incerteza, o acaso e a complexidade" envolvidos na atividade docente na medida em que chamam atenção para o fato de o resultado da ação docente depender da adesão do outro (o estudante), que, por sua singularidade, pode frustrar o professor, por mais cuidadoso que ele seja ao planejar, realizar o planejamento, avaliar a aprendizagem.

Tabela 7 Percepção sobre desafios.

\begin{tabular}{|c|c|c|}
\hline Desafio & $\begin{array}{l}\text { Nota } \\
\text { média }\end{array}$ & $\begin{array}{l}\% \\
\text { média }\end{array}$ \\
\hline Dispor de tempo para se dedicar ao estudo de questões pedagógicas & 3,48 & $69,5 \%$ \\
\hline Trabalhar com um grande número de estudantes por turma & 3,39 & $67,7 \%$ \\
\hline Orientar o ensino pela aprendizagem & 3,33 & $66,6 \%$ \\
\hline Mobilizar os estudantes para a aprendizagem & 3,33 & $66,5 \%$ \\
\hline Trabalhar com turmas muito heterogêneas (em repertório) & 3,28 & $65,6 \%$ \\
\hline Adotar recursos pedagógicos diversificados visando respeitar o perfil ... & 3,09 & $61,8 \%$ \\
\hline $\begin{array}{l}\text { Avaliar a aprendizagem: até que ponto os objetivos de aprendizagem } \\
\text { foram ... }\end{array}$ & 3,06 & $61,2 \%$ \\
\hline Explorar pedagogicamente recursos derivados da tecnologia digital & 2,99 & $59,8 \%$ \\
\hline Estabelecer um diálogo construtivo com as lideranças do curso & 2,85 & $57,1 \%$ \\
\hline Adequar os objetivos de aprendizagem à carga horária da disciplina & 2,81 & $56,3 \%$ \\
\hline Realizar feedback construtivo & 2,74 & $54,8 \%$ \\
\hline Estabelecer um diálogo construtivo com os estudantes & 2,74 & $54,8 \%$ \\
\hline Adequar os conteúdos aos objetivos de aprendizagem da disciplina & 2,72 & $54,4 \%$ \\
\hline Argumentar a relevância da disciplina para a formação dos estudantes & 2,71 & $54,3 \%$ \\
\hline Definir os objetivos de aprendizagem da disciplina & 2,54 & $50,8 \%$ \\
\hline
\end{tabular}

Fonte: Questionário aplicado, 2019. 


\section{Considerações Finais}

No conjunto da amostra, os professores têm elevada formação acadêmica, expressiva experiência com a docência superior, enfrentam exigente agenda semanal de trabalho na medida em que conciliam múltiplas atividades profissionais dentro e fora do ambiente acadêmico, que requerem múltiplas competências, tempo e muita dedicação. A totalidade dos respondentes sinaliza interesse pelas questões pedagógicas, embora parte deles aponte a limitação de tempo para se dedicar ao tema como o principal desafio enfrentado, e um grupo tenha declarado desinteresse pelos resultados deste levantamento. Por mais que o ensino orientado pela aprendizagem represente uma transformação paradigmática, que apenas uma parcela dos professores tenha formação em Educação e muitos tenham pouco tempo para se dedicar ao estudo da questão, afirmam-se proficientes nas principais atividades que envolvem ensino-aprendizagem. O que justifica questionarmos a efetiva consciência do nível de complexidade presente entre os vários desafios implicados nessa mudança de paradigma.

O processo de ensino-aprendizagem pressupõe a construção alicerçada de relações pedagógicas, para tanto, conhecer o estudante, construir relações pedagógicas pautadas pela confiança, na busca de ajustar a forma de trabalhar com ele, ganha centralidade no universo de uma pedagogia orientada para a aprendizagem. No entanto, há poucos indícios de que estamos de fato imbuídos desse propósito. Os objetivos de aprendizagem funcionam como a âncora do processo de ensino-aprendizagem. Isso equivale a afirmar que se definimos os referidos objetivos de forma equivocada, haverá repercussão sobre todo o processo de ensino-aprendizagem. Considerando os verbos utilizados, entre os 335 identificados, cabem duas observações: prevalecem objetivos de aprendizagem alinhados ao pensamento de ordem inferior (compreender, identificar, entender etc.) e objetivos de ensino (apresentar, capacitar, proporcionar etc.) que pouco contribuem para a aprendizagem. Mais do que isso, dificultam o processo de avaliação da aprendizagem - como avaliar "apresentar" "capacitar" ou "proporcionar" se são verbos alinhados a objetivos de ensino? - e de autorregulação do estudante. A avaliação em processo contribui para a gestão do ensino-aprendizagem e para a autorregulação dos estudantes, 
aspectos importantes quando se trabalha com adultos que requerem ambientes que favoreçam a promoção da autonomia responsável. Os dados apontam que os professores conseguem reconhecer parcialmente os desafios implicados nesse processo e o quanto ele contribui para o ensino e a aprendizagem. $O$ desafio relacionado à oferta de feedback é revelador.

Muito embora haja crescente compreensão da necessidade de formação pedagógica para um exercício mais adequado da docência universitária, "percebe-se certa desresponsabilização das instituições e das políticas públicas para com um movimento de profissionalização da docência da educação superior" (CUNHA, 2018, p. 22). A política pública voltada para a formação pedagógica do professor universitário é conhecidamente tímida e as ações institucionais se revelam muito pontuais, a exemplo da semana de planejamento. Frente a esse vazio, o mercado vem ocupado um espaço negligenciado pelo Estado e por grande parte das IES, criando soluções educacionais escaláveis, de natureza predominantemente instrumental. Contudo, o processo de formação pedagógica do professor universitário carece ser reconfigurado de modo mais amplo, crítico e rigoroso, afastando-se de modelos e prescrições aparentemente simples, rápidas, ajustadas a todos, desconsiderando a diversidade de situações encontrada em um País continental e assimétrico como o nosso.

A ausência de uma política de formação pedagógica do professor universitário, associada a crescente complexidade do trabalho docente, incidem sobre a necessidade de o professor criar ou fortalecer alianças. Nesse contexto, cresce a importância do coletivo, de uma comunidade que junta aprende a ensinar e a aprender (SORDI, 2019). Várias experiências em curso sinalizam a passagem de um professor individual, solitário e isolado para um trabalho conjunto, capaz de respeitar a diversidade de formas de organização pedagógica, sem negligenciar a cultura institucional. Não é sem razão de ser que as iniciativas que envolvem a integração e a interação, seja por meio de formação de redes, criação de parceiras ou composição de alianças, que no conjunto convergem para uma espécie de plataforma de cooperativas (hubs or active plataform) se multiplicam. Assim sendo, há um movimento de reforço da profissionalidade docente baseada na colaboração e na cooperação (NÓVOA, 2018). Nessa trilha é possível explorar o potencial da aprendizagem experiencial (KOLB, 1984), da aprendizagem situada, do trabalho coletivo resultante da participação em comunidades de interesse, sobretudo, aquilo 
que os anglo-saxões nomeiam de comunidade de prática (WENGER, 1998), mas cuja melhor tradução é comunidade de trabalho, comunidade profissional ou prática reflexiva (SCHON, 1992).

Resta-nos reafirmar o que professor António Nóvoa escreveu em um ensaio publicado há poucos meses, sugestivamente intitulado de $O$ futuro da universidade: o maior risco é não arriscar (2019, p.61) - "a revitalização da pedagogia exige um investimento intelectual idêntico ao que se faz na ciência e na investigação, exige a construção de novas práticas, a procura de novas maneiras de ensinar, um esforço para recuperar o entusiasmo perdido do gesto educativo".

Por fim, partilhamos uma reflexão geral: para aumento do impacto do Ensino Superior no País e no mundo, precisamos de Profissionais da Educação que desenvolvam as competências do Século XXI. Costumamos ensinar da forma como aprendemos, e seguindo essa lógica, para ensinar novas competências, precisamos ter desenvolvido tais competências em nós. A partir disso podemos contribuir para a aprendizagem dos estudantes, seja em cursos de graduação, tecnólogos ou stricto sensu. Nós, nossos Cursos e Programas, estamos enfrentando esse desafio?

\section{Referências}

ALCADIPANI, R. A hiperatividade do professor bombril. Organização \& Sociedade, v.2, n.35, 2005. Disponível em: https://portalseer.ufba.br/index.php/revistaoes/article/view/10811/0. Acesso em julho/2019. ALMEIDA, M. I. de; PIMENTA, S. G. Pedagogia universitária - valorizando o ensino e a docência na universidade. Revista Portuguesa de Educação, 27(2), 2014. Disponível em: http://www.scielo.mec.pt/pdf/ rpe/v27n2/v27n2a02.pdf. Acesso em julho/2019.

BLOOM B. S.; KRATHWOHL, D. R., MASIA, B. B. Taxonomia dos objetivos educacionais. vol.1 (domínio cognitivo). Porto Alegre: Globo, 1973.

COLET, N. R. Relève professorale: des forces fraîches dans la mêlée. In: Denis B.; Béchard, J.-P. Innover dans l'enseignement supérieur. Paris: PUF, 2009.

CUNHA, M. I. da. Docência na educação superior: a profissionalidade em construção. Educação, v. 41, n.1, p. 6-11, jan.-abr. 2018. Disponível em <file:///C:/Users/mclima/Downloads/29725-127564-2-PB\%20(1).pdf>. Acesso em: ago. 2019.

FERRAZ, A. P. do C. M.; BELHOT, R. V. Taxonomia de Bloom: revisão teórica e apresentação das adequações do instrumento para definição de objetivos instrucionais. Gestão \& Produção. v.17, n.2, 2010. Disponível em: http://www.scielo.br/scielo.php?script=sci_arttext\&pid=S0104-530X2010000200015\&lng=pt\&tlng=pt. Acesso em julho/2019 
FOWLER, F. J. Pesquisa de levantamento. Porto Alegre: Pensa, 2011.

GÜNTHER, H. Como elaborar um questionário. UNB, Laboratório de Psicologia Ambiental, Série Planejamento de Pesquisa nas Ciências Sociais, n.1, 2003.

HARARI, Y. N. 21 Lições Para o Século 21. São Paulo: Companhia das Letras, 2018.

HUBERMAN, M. O ciclo de vida profissional dos professores. In: NÓvOA, Antonio (org.) Vida de professores. 2 ed. Portugal: Porto Editora, 2000.

LANGRAFE, T. F.; BELTRÃO, K. e BERNDT, A. Análise dos Resultados dos ENADES 2009, 2012 e 2015 dos Cursos de Graduação em Administração (Oficina). Encontro Nacional dos Cursos de Graduação em Administração, Brasília, 2017.

LIMA, M.C.; TORINI, D. M.; SILVA, C. C. dos S. A transformação do processo de ensino e aprendizagem não é um voo de galinha. Associação Brasileira de Pesquisadores de Comunicação Organizacional e Relações Públicas - Abrapcorp (no prelo).

MORAES, M.C. A formação do educador a partir da complexidade e da transdisciplinaridade. Revista Diálogo Educacional. v.7, n.22, 2007. Disponível em < https://periodicos.pucpr.br/index.php/dialogoeducacional/article/view/4147>. Acesso em agosto/2019. MORAIS, C. Descrição, análise e interpretação de informação quantitativa - escalas de medida, estatística descritiva e inferência estatística. Bragança, Instituto Politécnico de Bragança, Escola Superior de Educação, 2010. Disponível em: http://www.ipb.pt/ cmmm/discip/ConceitosEstatistica.pdf. Acesso em agosto/2019.

NÓVOA, A. O futuro da universidade: o maior risco é não arriscar. Revista Contemporânea de Educação, v. 14, n. 29, jan/abr. 2019.

A modernização das universidades: memórias contra o tempo. Revista Portuguesa de Educação, vol.31, número Especial, out. 2018. Disponível em: http://www.scielo.mec.pt/scielo.php?script=sci_arttext\&pid=S0871-91872018000200003. Acesso em agosto/2019.

RUZ, S. P. da S.; RAMOS, N. B.; SILVA, K. A. C. P. C. da. Concepções de polivalência e professor polivalente: uma análise historico-legal. Revista Histedbr Online, Campinas, v.17, n.4 [74], p.118614, out./dez.2017. Disponível em; https://periodicos.sbu.unicamp.br/ojs/index.php/histedbr/article/ view/8645863/17403. Acesso em agosto/2019.

SCHÖN, D. Formar professores como profissionais reflexivos. In: NÓVOA, A. Os professores e a sua formação. Lisboa: Dom Quixote, 1992.

SOARES, S. R.; CUNHA, M. I. da. Programas de pós-graduação em educação: lugar de formação da docência universitária? Revista Brasileira de Pós-Graduação, Brasília, v.7, n.14, dez.2010.

SORDI, M. R. L. de. Docência no Ensino Superior: interpelando os sentidos e desafios dos espaços institucionais de formação. Educar em Revista, Curitiba, v. 35, n. 75, mai./jun. 2019. Disponível em: http:// www.scielo.br/pdf/er/v35n75/1984-0411-er-35-75-0135.pdf. Acesso em agosto/2019.

VASCONCELLOS, M. M. M.; SORDI, M. R. L. de. Formar professores universitários: tarefa (im)possível? Interface, 20 (57), Abr/Jun. 2016. Disponível em: https://doi.org/10.1590/1807-57622015.0450 https://www. scielosp.org/pdf/icse/2016.v20n57/403-414/pt. Acesso em agosto/2019. 